\title{
Predicting Sexual Intention to Engage in Premarital Sex Among Late Adolescent in Kuantan Government Secondary Schools: An Application of Theory of Planned Behaviour
}

\author{
Abdullah $F^{a}$, Draman $S^{a}$, Abd. Aziz $K H^{b}$, Zainuddin NA $A^{a}$, Muhammad NA \\ a Department of Family Medicine, Kulliyyah of Medicine, International Islamic University Malaysia, \\ 25200 Kuantan, Pahang \\ ${ }^{\mathrm{b}}$ Department of community Medicine, Kulliyyah of Medicine, International Islamic University Malaysia, 25200 \\ Kuantan, Pahang \\ c Department of Family Medicine, Faculty of Medicine, University Kebangsaan Malaysia, Jalan Yaakob 5600, \\ Cheras, Kuala Lumpur
}

\section{ABSTRACT}

Introduction: Based on the Theory of Planned Behaviour (TPB), sexual intention is determined by three main socio-cognitive factors which are permissive attitudes, social-norms and self-efficacy in performing premarital sexual activity. Premarital sex associated with increased risk of sexually transmitted diseases and detrimental social implications. The aim of this study was to explore the correlation of the socio-cognitive factors in predicting intention to engage in premarital sex amongst late adolescents in Kuantan government secondary schools. Method: This cross-sectional study was conducted among 466 pre-university students aged 18-19 years from nine government secondary schools in Kuantan district. A self-administered validated Youth Sexual Intention Questionnaire (YSI-Q) was used. Statistical analyses were done using IBM SPSS version 22.0. Results: Permissive attitude $(r=0.579, p<0.001)$, perception of social-norms $(r=0.513, p<0.001)$ and perceived self-efficacy $(r=0.253, p<0.001)$ were positively correlated with the sexual intention towards premarital sex. The higher the permissive attitude, social-norms and perceived self-efficacy, the higher the sexual intention score. There was a significant difference in the level of sexual intention between male (35.6\%) and female (64.4\%) with mean (SD) score of 10.54 (3.8) and 7.3 (2.9) respectively. Students with premarital sex experience $(1.5 \%)$ showed significantly higher score in sexual intention than student without premarital sex experience $(t=4.54, p<0.001)$. Conclusion: This study confirmed permissive attitude, perception of socialnorms and perceived self-efficacy were positively correlated with sexual intention towards premarital sex among the late adolescents. Therefore, it is important to consider this TPB theoretical framework in designing sexual abstinence intervention to curb the unsafe sexual behaviour.

KEYWORDS: socio-cognitive, sexual intention, premarital sex, secondary school

\section{INTRODUCTION}

The World Health Organization (WHO) defines adolescents as those people between 10 and 19 years

Corresponding Author:

Asst. Prof. Dr. Fa'iza binti Abdullah

Department of Family Medicine, Kulliyyah of Medicine, International Islamic University Malaysia, 25200 Kuantan, Pahang, Malaysia

Tel No : +609570400-2110

Email : drfaiza@iium.edu.my of age and they are further divided into early adolescence (10-14 years), middle adolescence (1517 years), and late adolescence (18-19 years). ${ }^{1}$ Early sexual initiation among adolescents is found to be associated with increasing risk to sexually transmitted infections. ${ }^{2}$ These early sexual initiators tend to engage in more risky behaviours, predisposing them for unwanted pregnancies, 
sexually transmitted diseases including human immunodeficiency virus (HIV) infection and cervical cancer. ${ }^{3}$ Early sexual initiation also contributes to the increment in the number of teenage pregnancies worldwide including here in Malaysia. From 2011 to 2013, it was reported that more than 18,000 girls with teenage pregnancy in Malaysia received health care service from the government clinics with $25 \%$ of them were unmarried. ${ }^{4}$ On average, there were 1,500 cases of teenage pregnancy in a month with 50 cases reported every day in Malaysia. ${ }^{5}$ Urbanization, modernization, and exposure to western culture had been perceived to have led to the invasion and erosion of Malaysian traditional beliefs and virtue about the importance of virginity on marriages. Consequently, it had contributed to more permissive attitude towards premarital sex among the adolescents. $^{6}$

Theory of Planned Behavior (TBP) is one of the sociocognitive theories that has been widely used in previous studies to predict health-related human behaviour. ${ }^{7}$ Hence, using the TBP as the foundation, this study hopes to increase our understanding on the complex issues related to adolescence sexual reproductive health. In TPB, human intention is guided by three perceptions:

i. Behavioural beliefs (perceived attitude on performing the behavior)

ii. Normative beliefs (perceived social norms)

iii. Control beliefs (perceived behavioural control or self-efficacy in implementing the action)

Thus, in designing any programme that aims to change people's behaviour, it is important to take into consideration the influence of the mentioned perceptions in determining one's intention and behaviour. The concept of TPB revealed that behavioural beliefs produce a permissive and nonpermissive attitude towards behaviours. ${ }^{8}$ Socialnorms explained perceived social pressure in performing the behaviour, which is influenced by the judgment of others such as parents, spouse, friends, and teachers. The approval and disapproval from others regarding what are being practiced by others influenced a person's behaviour. Self-efficacy is defined as the belief on a person's ability to perform a specific behaviour. It is affected by experience and environment that the person lives in, for example, if they do not have a sexual partner, having sex may be perceived as difficult indicating low level of selfefficacy. ${ }^{9}$ The linear combination of the three perceptions (attitude, social-norm, and self-efficacy) directly influence behavioural intention which in turn affect the actual action. In summary, higher permissive attitude, perceived social-norm and selfefficacy will lead to higher intention to perform the behavior. In the context of this study, intention is referred to as sexual intention and the behaviour is premarital sexual activity.

The prevalence of adolescents engaging in premarital sex varies among the local studies conducted across Malaysia, ranging between $5 \%$ to $13 \%$ in which $4.6 \%$ in Selangor, 5.4\% in Negeri Sembilan and 12.6\% in Pulau Pinang. ${ }^{10-12}$ The differences in the target age group in each study and diversities in collecting the data contribute to the variation in the results.

In the National Health Morbidity Survey in 2017, Pahang was reported as the highest state, in which 9.5\% of the adolescents aged between 13 to 17 years were sexually experienced. ${ }^{13}$

There are limited local studies that have investigated adolescent sexual intention in particular using the socio-cognitive theory. ${ }^{14}$

This study was therefore intended to fill this gap. Using the Theory of Planned Behavior (TBP), this study aimed to identify association between sociocognitive factors (permissive attitude, perceived social norm, and perceived self-efficacy) and intention towards premarital sex activity among school-going late adolescent in Kuantan, Pahang. 


\section{MATERIALS AND METHODS}

Prior to conducting this study, the researcher received appropriate permission from Ministry of Education, Pahang State Education Department, Kuantan Education Department and the schools' principals. During the time of data collection, there were nine government secondary schools that provided pre-university programme under the Ministry of Education. The schools' principals were contacted, briefed, and invited to participate in the study. A cross-sectional study was conducted from March 2018 until June 2018, involving pre-university students aged 18 to 19 years old in Kuantan, Pahang. These adolescents were studying and attending government secondary school session 2017/18 in Kuantan district. The minimum sample size was 465 , calculated based on a single proportion formula using OpenEpi version 3. The inclusion criteria were Malaysian citizen, students who gave their informed consent, students who were studying in government schools, aged 18 to 19 years old and able to understand and write in Malay and English. Exclusion criteria were students who were absent on data collection day and students who were married. From all nine secondary schools in Kuantan district, 466 students fulfilled the study criteria and all of them were recruited.

All the students received a set of self-administered anonymous questionnaire which had 12 questions on socio-demographic profiles and 20 items in YSI-Q. The 20 items in $\mathrm{YSI}-\mathrm{Q}$ covered 4 main constructs (permissive attitude, perceived social norms, perceived self-efficacy and sexual intention) with 4points Likert-type scale of responses of 1 (strongly disagree), 2 (disagree), 3 (agree) and 4 (strongly agree). ${ }^{15}$

Data was entered into IBM SPSS version 22.0 and a few steps were taken in order to ensure high quality data that include codebook, data screening, data cleaning, and missing data management. Categorical variables (gender, ethnicity, religion, household income, parent's education level, tobacco use, dating status and prior sexual experience) were presented in frequency (\%) whereas the numerical variables (attitude, social norm, self-efficacy and sexual intention) were presented in mean (standard deviation) or median (interquartile range [IQR]). Respondents were regarded as ever had premarital sex if they answered yes to the question of have you ever had sexual intercourse (at any point of time). Bivariate analysis such as Chi-square, student t-test or correlation analysis were used to determine the relationship between attitude, social norms and self -efficacy and sexual intention. A p-value of less than 0.05 was taken as statistical significance.

Ethical clearance was obtained from the IIUM Ethics Committee (IREC 2017-063). The study is funded by IIUM Research Initiative Grant Scheme (RIGS17-0650640).

\section{RESULTS}

The demographic background is presented in Table1. A total of 466 students participated in this study, predominantly Malay (67.4\%) and females (64.4\%) with Chinese $(28.5 \%)$ being the second largest respondents, followed by Indian $(1.9 \%)$ and others $(2.1 \%)$. In terms of religion, majority were Muslims (68.2\%), followed by Buddhist (26.4\%), Christian $(3.2 \%)$, Hindu (1.7\%) and others (0.4\%). Most of the students' parents had up to secondary level of education where $61.2 \%$ for fathers and $65.7 \%$ for mothers respectively and less than a third of the parents had tertiary education $(28.3 \%$ for fathers and $24,7 \%$ for mothers).

Many of the students came from low-income families $(63.7 \%$ ) with a median monthly family income of RM 2550 (IQR RM 1500-4500). More than half of the students reported that they do not have a dating partner (54.3\%) at that current moment and $81.8 \%$ students have never smoke. 
Figure-1 showed that the prevalence of premarital sex among late adolescents in Kuantan government schools was $1.5 \%$. This can be translated as less than 2 in 100 late adolescents had revealed their experience of performing sexual activity.

Table-1: Sociodemographic Background of Respondents $(n=466)$

\begin{tabular}{|c|c|}
\hline Independent Variables & $n(\%)$ \\
\hline \multicolumn{2}{|l|}{ Age } \\
\hline 18 & $298(63.9)$ \\
\hline 19 & $168(36.1)$ \\
\hline \multicolumn{2}{|l|}{ Gender } \\
\hline Male & $166(35.6)$ \\
\hline Female & $300(64.4)$ \\
\hline \multicolumn{2}{|l|}{ Religion } \\
\hline Muslim & $318(68.2)$ \\
\hline Non-Muslim & $148(31.8)$ \\
\hline \multicolumn{2}{|l|}{ Ethnicity } \\
\hline Malay & $314(67.4)$ \\
\hline $\begin{array}{l}\text { Non-Malay } \\
\text { Father Education }\end{array}$ & $152(32.6)$ \\
\hline $\begin{array}{l}\text { Non-schooling/non-formal/ } \\
\text { guardian }\end{array}$ & $15(3.2)$ \\
\hline Primary & $34(7.3)$ \\
\hline Secondary & $285(61.2)$ \\
\hline $\begin{array}{r}\text { Tertiary } \\
\text { Mother Education }\end{array}$ & $132(28.3)$ \\
\hline $\begin{array}{l}\text { Non-schooling/non-formal/ } \\
\text { guardian }\end{array}$ & $9(1.9)$ \\
\hline Primary & $36(7.7)$ \\
\hline Secondary & $306(65.7)$ \\
\hline $\begin{array}{c}\text { Tertiary } \\
\text { Total Household income }\end{array}$ & $115(24.7)$ \\
\hline Low income & $297(63.7)$ \\
\hline Middle income & $163(35)$ \\
\hline $\begin{array}{l}\text { High income } \\
\text { Smoking Status }\end{array}$ & $6(1.3)$ \\
\hline Non-smoker & $378(81.8)$ \\
\hline $\begin{array}{l}\text { Ever smoke } \\
\text { Dating Status }\end{array}$ & $88(18.9)$ \\
\hline No & $253(54.3)$ \\
\hline Yes & $213(45.7)$ \\
\hline
\end{tabular}

There is an association between gender and premarital sex activity. The proportion of males who had premarital sex experience is significantly higher than the female presented in Figure-II.

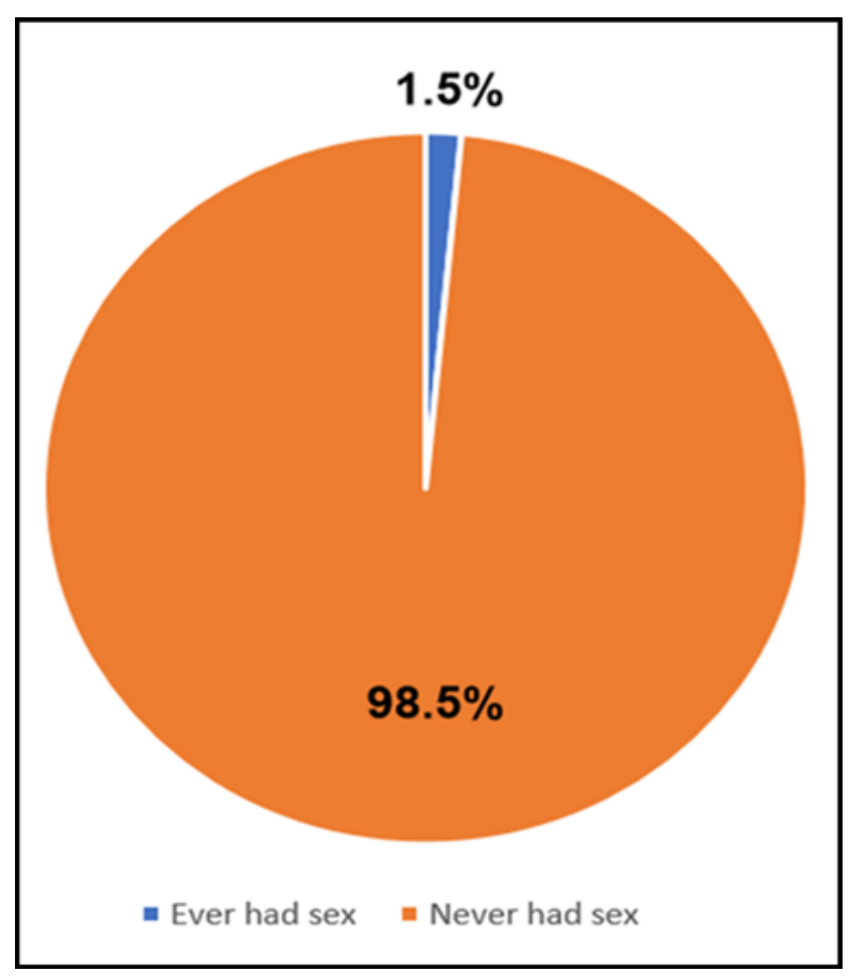

Figure 1: Prevalence of Premarital Sex Among Late Adolescents in Kuantan Government School $(n=466)$

From Table-II, male respondents showed significantly higher sexual intention compared to female students $(p=0.009)$ and those with premarital sexual experience showed higher score in sexual intention compared to the counterparts.

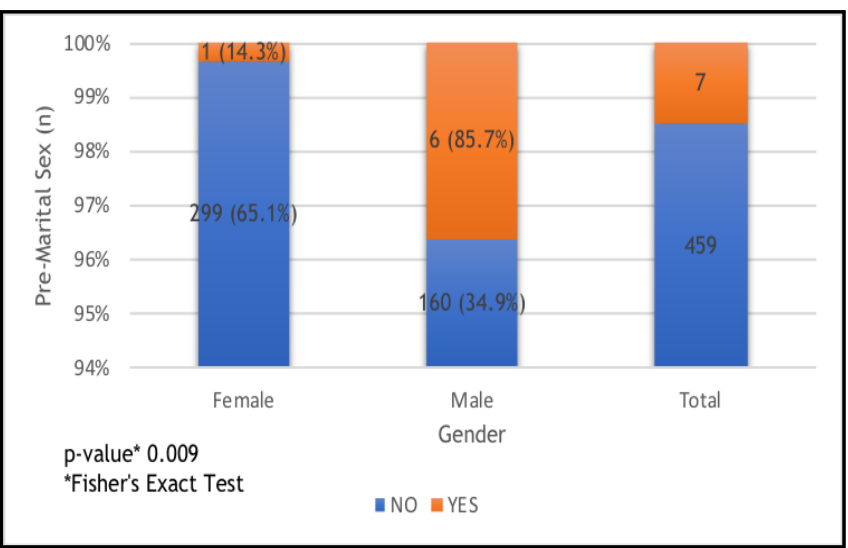

Figure-II: The Association Premarital Sex Experience Between Gender $(n=466)$

Table-III showed the level of correlation between permissive attitude, social norms, self-efficacy with sexual intention. All the three variables were positively correlated with sexual intention, with permissive attitude showing the higher correlation value $(r)$, followed by social-norms and self-efficacy. 
Table-II: The Association of Sexual Intention Between Gender and Premarital Sex (n-466)

\begin{tabular}{|c|c|c|c|c|c|}
\hline \multirow{4}{*}{ Gender } & Variables & $\begin{array}{l}\text { Sexual Intention } \\
\text { Mean (SD) }\end{array}$ & $\begin{array}{l}\text { Mean difference }(95 \% \\
\mathrm{Cl})\end{array}$ & $\begin{array}{l}\text { t-statistic } \\
(d F)\end{array}$ & $p$-value* \\
\hline & Male & $10.54(3.816)$ & & & \\
\hline & & & 3.406 & $10.790(464)$ & 0.000 \\
\hline & Female & $7.13(2.913)$ & $(2.786,4.026)$ & & \\
\hline \multirow{3}{*}{ Premarital Sex } & No & $8.25(3.853)$ & \multirow{3}{*}{$\begin{array}{c}-6.178 \\
(-8.851,-3.505)\end{array}$} & \multirow{3}{*}{$-4.542(464)$} & \multirow{3}{*}{0.000} \\
\hline & & & & & \\
\hline & Yes & $14.43(2.507)$ & & & \\
\hline
\end{tabular}

*Independent $t$ test

\section{DISCUSSION}

The profiles of students who were involved in this level scientific knowledge. Hence, there is a study matched the typical government school possibility that they had essential knowledge on secondary students in Malaysia with more than half sexual and reproductive health leading to lower of them being Malays and females. ${ }^{16}$ Most of the intention towards premarital sex. Students with high respondents came from low-income families, earning knowledge on sexual reproductive health were less less than RM3000 per month. ${ }^{17}$ As with earlier likely to perform any sexual activity. ${ }^{12}$ In addition, as studies, most of the parents had up to secondary mentioned earlier, the prevalence of adolescents level of education. ${ }^{18-19}$ Nearly half of the respondents had dating partners $(45.7 \%)$ at any point in their life which was consistent with an earlier study that found $44 \%$ of the respondents had ever dated. ${ }^{20}$ Nearly one fifth of the respondents $(18.9 \%)$ ever smoked tobacco, which was slightly higher compared to the NHMS conducted in 2017 and Malaysian Adolescent High-Risk Behavior survey by MyaHRB (2013: 14.6\%). ${ }^{13,20}$ This study showed that the prevalence of premarital sex and sexual intention among late adolescents in Kuantan government schools was low. This low prevalence could be because of the social desirability bias in which the respondents may not be forthcoming in declaring their experience as it is against the social norms to practice sexual activity before marriage as premarital sex is generally not accepted in Malaysia. On the other hand, the students were those who had sat for the national school exit exam (Sijil Pelajaran Malaysia), and thus were most likely to have at least a good basic SPMever having sex varied among the local studies conducted in different states of Malaysia and these differences are related to different age groups, settings and method of conducting the surveys. ${ }^{12}$

Table-III: The Correlation Between Permissive Attitude, Social Norms, Self-Efficacy and Sexual Intention ( $n=466)$.

\begin{tabular}{lll}
\hline Variables & \multicolumn{2}{l}{ Sexual Intention } \\
\cline { 2 - 3 } & $r$ & $p$ value \\
Permissive Attitude & $.579^{* *}$ & $<0.001$ \\
Social Norms & $.513^{* *}$ & $<0.001$ \\
Self-efficacy & $.253^{* *}$ & $<0.001$ \\
\hline${ }^{* *}$ Correlation is significant at the 0.01 level (2-tailed)
\end{tabular}

There was a strong association between gender and sexual intention as well as premarital sexual activity. The male predominant pattern of ever-sexually active found in this study was similar with earlier studies conducted among adolescents in Singapore and 
Malaysia. ${ }^{22,23}$ Similarly, the higher prevalence of male students with sexual intention was comparable with a local study conducted among college students aged 18-22 years in Klang Valley. ${ }^{18}$ This male dominant pattern could be related to the Malaysian social norms where males will be less stigmatized while females tend to be labeled and blamed for getting pregnant or for contracting sexually transmitted infection. $^{24}$

This study also demonstrated that students with sexual intention were significantly associated with premarital sexual activities. Based on the Theory of Planned Behaviour, in a situation when a person has full control of his or herself, intention is the most proximal determinant of behaviour. This relationship; that is sexual intention being the proximal factor that predicts premarital sex among adolescent, has been shown previously by two studies. ${ }^{7,25}$ This study also confirmed the Theory of Planned Behaviour in which permissive attitude, perception of social norms (peer pressure) and self-efficacy were positively correlated with sexual intention to perform premarital sexual activity.

\section{CONCLUSION}

The Theory of Planned Behaviour (TBP) stated that sexual intention is significantly associated with premarital sex behaviour. This study proved that TPB in which permissive attitude, social-norms and selfefficacy influenced sexual intention to perform premarital sexual behaviour with stronger relationship with the attitude and perception of social-norms. Although this study found a low prevalence of ever had sex, these late adolescents should receive equitable and effective sexual education programme and hopefully, to lower their intention of premarital sex and correct their perceptions (attitude, social-norms and self-efficacy) toward premarital sex. Additionally, this study should be replicated among other populations such as street adolescents, early and middle adolescents as well as those in institutions. Due to the unique nature of Malaysian population, there is a need to develop a culturally specific sex education programme addressing important domains including the permissive attitude and social-norms.

\section{CONFLICT OF INTEREST}

None

\section{ACKNOWLEDGEMENT}

We would like to express our gratitude to the Ministry of Education Malaysia, Pahang Education Department, Kuantan Education Department and all schools which were involved in the data collection for their support to conduct the study. This Research was funded by University Research Initiative Grant Scheme (RIGS17-065-0640).

\section{REFERENCES}

1. Feldman SS, Elliott GR. At the threshold: The developing adolescent. Cambridge, MA, US Harvard Univ Press. 1990;(1990):642.

2. Forhan SE, Gottlieb SL, Sternberg MR, Xu F, Datta SD, McQuillan GM, et al. Prevalence of Sexually Transmitted Infections Among Female Adolescents Aged 14 to 19 in the United States. Pediatrics. 2009;124(6):1505-12.

3. Ma Q, Ono-Kihara M, Cong L, Xu G, Pan X, Zamani $S$, et al. Early initiation of sexual activity: a risk factor for sexually transmitted diseases, HIV infection, and unwanted pregnancy among university students in China. BMC Public Health. 2009;9:111.

4. Suan MAM, Ismail AH, Ghazali H. A review of teenage pregnancy research in Malaysia. Med $\mathrm{J}$ Malaysia. 2015;

5. Suan MAM, Ismail AH, Ghazali H. A review of teenage pregnancy research in Malaysia. Med $\mathrm{J}$ Malaysia. 2015;70(4):214-9. 
6. Wong LP. Qualitative Inquiry into Premarital Sexual Behaviours and Contraceptive Use among Multiethnic Young Women: Implications for Education and Future Research. PLoS One. 2012;7(12).

7. Protogerou C, Flisher AJ, Aar LE, Mathews C. The theory of planned behaviour as a framework for predicting sexual risk behaviour in sub-Saharan African youth: A critical review. Journal of Child and Adolescent Mental Health. 2012.

8. Ajzen I. The theory of planned behavior. Organ Behav Hum Decis Process Organ Behav Hum Decis Process. 1991;50(2):179-211.

9. Rew L. Adolescent health: A multidisciplinary approach to theory, research, and intervention. Adolescent Health: A Multidisciplinary Approach to Theory, Research, and Intervention. 2005.

10. Anwar M, Sulaiman SA, Ahmadi K, Khan TM. Awareness of school students on sexually transmitted infections (STIs) and their sexual behavior: a cross-sectional study conducted in Pulau Pinang, Malaysia. BMC Public Health [Internet]. 2010;10. Available from: https:// doi.org/10.1186/1471-2458-10-47

11. Lee LK, Chen PCY, Lee KK, Kaur J. Premarital sexual intercourse among adolescents in Malaysia: A cross-sectional Malaysian school survey. Singapore Med J. 2006;47(6):476-81.

12. Wong LP. An exploration of knowledge, attitudes and behaviours of young multiethnic Muslim-majority society in Malaysia in relation to reproductive and premarital sexual practices. BMC Public Health [Internet]. 2012;12:865. Available from: http:// www.ncbi.nlm.nih.gov/pubmed/23057505\%

5Cnhttp://www.ncbi.nlm.nih.gov/ pubmed/23057505

13. Awaluddin SM, Yusof M, Mohd Yusoff MF, Aris T, Ahmad N, Yoep N, et al. National Health and Morbidity Survey 2017: Adolescent Health
Survey 2017. 2018.

14. Muhammad NA, Shamsuddin K, Mohd Amin R, Omar K, Thurasamy R. Questionnaire development and validity to measure sexual intention among youth in Malaysia. BMC Public Health. 2017;17(1):157.

15. Muhammad NA, Shamsuddin K, Mohd Amin R, Omar K, Thurasamy R. Questionnaire development and validity to measure sexual intention among youth in Malaysia. BMC Public Health. 2017;

16. Ismail L. Gender gap in higher education: Perspective on factors influencing enrolment in Malaysian universities: A University of Malaya sample. Online J Qual High Educ. 2015;

17. Department of Statistic Malaysia. Department of Statistics Malaysia Press Release. Dep Stat Malaysia. 2016;

18. Muhammad N, Tohid H, Omar K, Mohd. Amin R, Shamsuddin K. Gender Difference in the Influence of Family Interaction and Parenting Behaviours on Youth Sexual Intention. Soc Sci [Internet]. 2017;6(3):105. Available from: http://www.mdpi.com/2076-0760/6/3/105

19. Rahman AA, Rahman RA, Ibrahim MI, Salleh $H$, Ismail SB, Ali SH, et al. Knowledge of sexual and reproductive health among adolescents attending school in Kelantan, Malaysia. Southeast Asian J Trop Med Public Health. 2011;42(3):717-25.

20. Zulkifli SN, Low WY. Sexual practices in Malaysia: Determinants of sexual intercourse among unmarried youths. J Adolesc Heal. 2000;27(4):276-80.

21. $\operatorname{Lim} \mathrm{KH}, \operatorname{Lim} \mathrm{HL}$, Teh $\mathrm{CH}$, Kee CC, Khoo $\mathrm{YY}$, Ganapathy SS, et al. Smoking among schoolgoing adolescents in selected secondary schools in Peninsular Malaysia- findings from the Malaysian Adolescent Health Risk Behaviour (MyaHRB) study. Tob Induc Dis. 2017; 
22. Ahmad N, Awaluddin SM, Ismail H, Samad R, NikAbdRashid N. Sexual Activity Among Malaysian School-Going Adolescents. Asia Pacific J Public Heal [Internet]. 2014;26 (5_suppl):44S-52S. Available from: http:// journals.sagepub.com/ doi $/ 10.1177 / 1010539514544700$

23. Emmanuel S, Bishop G, Wong M-L, Lim F-S, Chan RK-W, Koh D, et al. Premarital Sexual Intercourse Among Adolescents in an Asian Country: Multilevel Ecological Factors. Pediatrics. 2009;124(1):e44-52.

24. Mensch BS, Clark WH, Anh DN. Adolescents in Vietnam: Looking beyond reproductive health. Stud Fam Plann. 2003;

25. Cha ES, Doswell WM, Kim KH, CharronProchownik D, Patrick TE. Evaluating the Theory of Planned Behavior to explain intention to engage in premarital sex amongst Korean college students: A questionnaire survey. Int J Nurs Stud [Internet]. 2007 [cited 2017 May 26];44(7):1147-57. Available from: http:/ /

www.sciencedirect.com.ezlib.iium.edu.my/ science/article/pii/S0020748906001301 